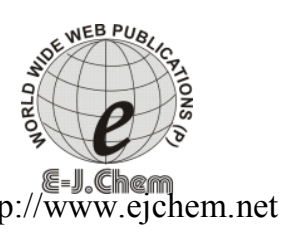

ISSN: 0973-4945; CODEN ECJHAO

E-Journal of Chemistry

2012, 9(2), 1042-1046

\title{
A New Nano Silica Gel Supported by Thionyl Chloride as a Solid Acid for the Efficient Diazotization of Aniline Derivatives: Application and Synthesis of Azo Dyes
}

\author{
MOHAMMAD MIRJALILI ${ }^{\text {} *}$, FATEMEH ZAHED ${ }^{\S}$ and ALIREZA HASSANABADI \\ ${ }^{\S}$ Faculty of Textile Engineering, Yazd Branch, \\ Islamic Azad University, Yazd, Iran \\ Department of Chemistry, Islamic Azad University, \\ Zahedan Branch, P.O. Box 98135-978, Zahedan, Iran \\ mir_textile@yahoo.com
}

Received 27 August 2011; Accepted 14 October 2011

\begin{abstract}
A new nano silicagel supported by thionyl chloride as a solid acid was synthesized and used as a increasing the production yield of dye to affect the efficient diazotization of arylamines. The diazonium salts thus obtained were coupled, using standard experimental procedures, to anilines and naphthols to afford the requisite azo dyes in good yield. The diazotization and subsequent azo-coupling generated the related azo dyes at low temperature in short reaction times with a simple experimental procedure.
\end{abstract}

Keywords: Azo dyes, Nano silicagel, Azo-coupling, Diazotization, 2-Naphthol, Solid acid.

\section{Introduction}

Azo compounds are considered to be the most widely used class of industrial synthesized organic dyes due to their versatile applications in various fields, such as dyeing textile fiber, biological-pharmacological activities and advanced application in organic synthesis ${ }^{1-6}$. The usual azo dyes synthesis methods require some difficult conditions like low temperature, high pressure and also the use of dense liquid acids ${ }^{7-9}$. These problems can be removed by using nano solid acids. Solid acid catalysts have served as important functional materials for chemicals production. Processes involving conventional acids are, however, typically associated with problems of high toxicity, catalyst waste, use of a large amount of catalyst, and difficulty of recycling. Replacement of liquid acids with solid ones is desirable in chemical industry because solid acids are environmentally friendly with respect to corrosiveness, safety, reduced waste and ease of use ${ }^{10,11}$.

Many studies have reported the diazotization of aniline derivatives ${ }^{12-16}$. Lyčka and coworkers reported the synthesis of some phenylazonaphthols in 1-butyl-3-methylimidazolium tetrafluoroborate using a coupling reaction of (4-x-benzene)diazonium tetrafluoroborates $\left(\mathrm{X}=\mathrm{H}\right.$ and NO2) with 1 - and 2-naphthols and their sodium salts ${ }^{17}$. Noroozi et al. synthesized 
azo dyes via diazotization of aniline derivatives and subsequent azo-couplings in the presence of $p$-toluenesulfonic acid by grinding ${ }^{18}$.

The use of nano solid acid in azo dyes synthesis increases the production yield of dye and reduces the period of time that is required for dye synthesis. Another problem that can be tackled by this method refers to the unstability of diazonium salt solution, The diazonium salt is unstable at room temperature in usual methods of azo dyes synthesis, and would become stable via the use of the method presented in this paper.

\section{Experimental}

Melting points were determined with an Electrothermal 9100 apparatus. Elemental analyses were performed using a Costech ECS 4010 CHNS-O analyzer at analytical laboratory of Islamic Azad University Yazd branch. Fourier transform infrared (FTIR) spectra were recorded on a Shimadzu 8400 FTIR spectrophotometer. The UV-Visible spectra were obtained on a Varion Carry 100 Scan spectrometer. ${ }^{1} \mathrm{H}$ and ${ }^{13} \mathrm{C}$ NMR spectra were recorded on Bruker DRX-500 Avance spectrometer at solution in $\mathrm{CDCl}_{3}$ using TMS as internal standard. The chemicals used in this work were purchased from Fluka (Buchs, Switzerland) and were used without further purification.

General Procedure for Preparation of Nano Silicagel Supported by Thionyl Chloride:

Nano silicagel $(5 \mathrm{~g})$ with a particle size of $20 \mathrm{~nm}$ was placed in oven for $1 \mathrm{~h}$ in order to activate it. Thionyl chloride $(10 \mathrm{~mL})$ was then added gradually over $15 \mathrm{~min}$ and the reaction continued for $1 \mathrm{~h}$ with stirring. The temperature of the mixture was then increased to $70^{\circ} \mathrm{C}$. The resulting compound was placed in vaccum desicator for $24 \mathrm{~h}$ to obtain the white powder of nano silicagel supported by thionyl chloride.

\section{General Procedure for Preparation of Compounds $(\mathbf{3 a}, \boldsymbol{b})$}

To a magnetically stirred solution of 2-aminobenzoic acid 1 (1 mmol) and sodium nitrite $(2 \mathrm{~mL}, 10 \%)$ in acetone $(10 \mathrm{~mL})$ was added supported nano silicagel $(0.04 \mathrm{~g})$. The reaction mixture was then stirred for $10 \mathrm{~min}$ at room temperature, while stirring to obtain diazonium salt solution 2. The resulting diazonium salt was slowly added to the solution of 2-naphtol $(1 \mathrm{mmol})$ in acetone and sodium hydroxide $(5 \mathrm{~mL}, 5 \%)$ and was added to adjust the $\mathrm{pH}$ to 6-7, the reaction mixture was then stirred for $10 \mathrm{~min}$ at room temperature. The solvent was evaporated at reduced pressure. The residue was precipitated, filtered and washed with diethyl ether to give the pure product 3.

\section{2-(2-Hydroxy-naphthalen-1-ylazo)-benzoic acid (3a)}

Yield: 92\%; Brown powder; m.p. 148-150 ${ }^{\circ}$ C. IR $(\mathrm{KBr})\left(v_{\max }, \mathrm{cm}^{-1}\right): 3424(\mathrm{OH}), 1693(\mathrm{C}=\mathrm{O}$, acid), 1588, 1529, 1448. Analyses: Calcd. For $\mathrm{C}_{17} \mathrm{H}_{12} \mathrm{~N}_{2} \mathrm{O}_{3}(292)$ : C, 69.86; H, 4.14; N, 9.58. Found: C, 69.72; H, 3.96; N, 9.65. ${ }^{1} \mathrm{HNMR}(500 \mathrm{MHz}, \mathrm{CDCl} 3) \delta(\mathrm{ppm}): 12.18(2 \mathrm{H}$, broad s, 2OH), $8.06(1 \mathrm{H}, \mathrm{dd}, J=7$ and $2 \mathrm{~Hz}), 7.69(2 \mathrm{H}, \mathrm{m}), 7.54(1 \mathrm{H}, \mathrm{d}, J=7 \mathrm{~Hz}), 7.41(1 \mathrm{H}, \mathrm{dd}, J=7$ and $2 \mathrm{~Hz}), 7.41(1 \mathrm{H}, \mathrm{dt}, J=7$ and $2 \mathrm{~Hz}), 7.49(1 \mathrm{H}, \mathrm{d}, J=7 \mathrm{~Hz}), 7.35(1 \mathrm{H}, \mathrm{dt}, J=7 \mathrm{and} 2 \mathrm{~Hz}), 7.11(2 \mathrm{H}$, m). ${ }^{13} \mathrm{C}$ NMR $(125.8 \mathrm{MHz}, \mathrm{CDCl} 3) \delta(\mathrm{ppm}): 172.64,140.07,138.24,135,37,133.25,131.17$, $128.90,128.29,127.61,124.50,121.45,120.41,120.13,119.24,117.09,116.46,110.33$.

\section{4-(2-Hydroxy-naphthalen-1-ylazo)-benzoic acid (3b)}

Yield: 94\%; Brown powder; m.p. 139-141 ${ }^{\circ} \mathrm{C}$. IR $(\mathrm{KBr})\left(v_{\max }, \mathrm{cm}^{-1}\right): 3430(\mathrm{OH}), 1694(\mathrm{C}=\mathrm{O}$, acid), 1599, 1493, 1442. MS (m/z, \%): $364\left(\mathrm{M}^{+}, 4\right)$. Analyses: Calcd. for $\mathrm{C}_{21} \mathrm{H}_{17} \mathrm{ClN}_{2} \mathrm{O}_{2}: \mathrm{C}$, 69.14; H, 4.70; N, 7.68. Found: C, 69.3; H, 4.6; N, 7.5. ${ }^{1} \mathrm{HNMR}(500 \mathrm{MHz}, \mathrm{CDCl} 3) \delta$ (ppm): $11.83(2 \mathrm{H}$, broad s, 2OH), $7.68(1 \mathrm{H}, \mathrm{d}, J=7 \mathrm{~Hz}), 7.62(1 \mathrm{H}, \mathrm{d}, J=7 \mathrm{~Hz}), 7.50(1 \mathrm{H}$, 
dd, $J=7$ and $2 \mathrm{~Hz}), 7.44(1 \mathrm{H}, \mathrm{dt}, J=7$ and $2 \mathrm{~Hz}), 7.40(1 \mathrm{H}, \mathrm{dt}, J=7$ and $2 \mathrm{~Hz}), 8.28(1 \mathrm{H}, \mathrm{dd}$, $J=7$ and $2 \mathrm{~Hz}), 7.63(2 \mathrm{H}, \mathrm{d}, J=7), 7.52(2 \mathrm{H}, \mathrm{d}, J=7) \cdot{ }^{13} \mathrm{C}$ NMR $(125.8 \mathrm{MHz}, \mathrm{CDCl} 3) \delta$ (ppm): 171.85, 140.29, 139.15, 135,18, 128.8, 128.06, 127.45, 124.72, 121.53, 120.37, $120.28,119.12,116.94,115.28,111.24$.

\section{Results and Discussion}

We now introduce a new nano silicagel supported by thionyl chloride as a solid acid that can act as increasing the production yield of dye for the efficient conversion of aryl amines to their corresponding diazonium salts. Azo-coupling of these diazonium salts afforded the related azo dyes in good yields (Figure 1).

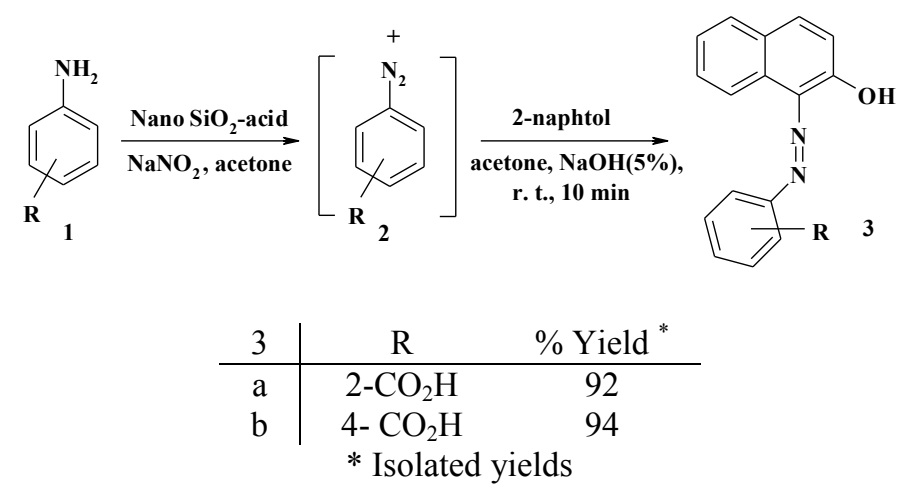

Figure 1. Diazotization of anilines using nano silicagel supported by thionyl chloride as a solid acid and diazo-coupling with 2-naphtole.

The structures of compounds $\mathbf{3 a}, \mathbf{b}$ were deduced from their elemental analyses and their IR, ${ }^{1} \mathrm{H}$ NMR, ${ }^{13} \mathrm{C}$ NMR spectra. The dyes were applied to wool and nylon fibers, and their technical properties on the fibers were investigated. Dyeing was carried out in a Rota dyer (Nasaj Sanat Yazd) using a liquor ratio of 40:1, $\mathrm{pH}=5-5.5$ (acetic acid) at 1.5\% o.m.f. (Figure 2).

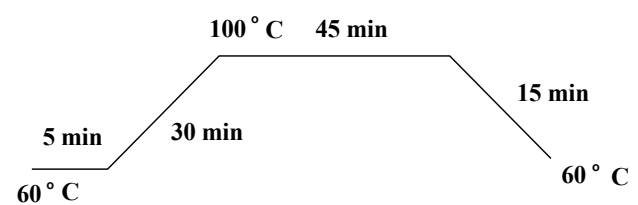

Figure 2. Dyeing profile of the synthesized dyes.

At the end of dyeing, the excess dye was removed by subjecting the dyeing to conventional alkali clearing which was undertaken using a 50:1 liquor ratio, $2.5 \mathrm{~g} / \mathrm{L}$ sodium hydroxide and $1 \mathrm{~g} / \mathrm{L}$ detergent for $30 \mathrm{~min}$ at $80^{\circ} \mathrm{C}$. The alkali cleared samples were rinsed and allowed to dry.

The absorbance of the dye solution was measured at the wavelength of maximum absorption $\left(\lambda_{\max }\right)$ of the dye using a UV-Visible spectrophotometer. The exhaustion E of the dyes on the fibers was calculated according to Eq. 


$$
E \%=\left(1-\frac{A_{1}+A_{2}}{A_{0}}\right) \times 100
$$

Where $A_{0}$ and $A_{1}$ are the absorbance values of the dye-bath before and after the dyeing process, respectively and $A_{2}$ is the absorbance value of the clearing-bath.

The cleared, dyed fabrics were tested according to the AATCC 107-2002 wash test. The change in shade and staining of adjacent multifibre was assessed using the S.D.C gray scales. A light fastness test was carried out in accordance with the ATCC 16-2004 test method.

The maximum exhaustion(E\%) and the wavelength of maximum absorption $\left(\lambda_{\max }\right)$ for both dyes are presented in Table 1 and the fastness properties of the novel synthesized azoic dyes on nylon and wool are listed in Table 2 .

Table 1. UV-Vis spectral properties of synthesized dyes.

\begin{tabular}{ccccc}
\hline \multirow{2}{*}{ Dye } & \multirow{2}{*}{$\lambda_{\max }$} & \multirow{2}{*}{$\begin{array}{c}\text { Absorption } \\
\text { Equation }\end{array}$} & Exhaustion & Percent $(\mathrm{E} \%)$ \\
\cline { 4 - 5 } & & Nylon & Wool \\
\hline 1 & 488 & $\mathrm{Abs}=2.82 \times$ Conc & 57.87 & 68.64 \\
2 & 432 & Abs $=4.68 \times$ Conc & 56.81 & 70.66 \\
\hline
\end{tabular}

Table 2. The fastness test of dyes on wool and nylon.

\begin{tabular}{|c|c|c|c|c|c|c|c|c|c|}
\hline \multirow{3}{*}{ Dye } & \multirow{3}{*}{ Fiber } & \multirow{3}{*}{$\begin{array}{l}\text { Light } \\
\text { Fastness }\end{array}$} & \multicolumn{5}{|c|}{ Washing Fastness } & & \\
\hline & & & \multirow{2}{*}{$\begin{array}{l}\text { change } \\
\text { in color }\end{array}$} & & \multicolumn{5}{|c|}{ Staining } \\
\hline & & & & Wool & Acrylic & Nylon & PET & Cotton & Acetate \\
\hline \multirow{3}{*}{1} & Wool & 6 & $4-5$ & 4 & 5 & 4 & 5 & $4-5$ & 5 \\
\hline & Nylon & $3-4$ & 4 & 4 & 5 & 4 & 5 & 4 & 5 \\
\hline & Wool & $7-8$ & $4-5$ & 3 & $4-5$ & 4 & 5 & 5 & 5 \\
\hline 2 & Nylon & 4 & $4-5$ & $3-4$ & $4-5$ & 4 & 5 & 5 & 5 \\
\hline
\end{tabular}

\section{Conclusion}

In summary, two azo dyes containing $\mathrm{COOH}$ group have been synthesized by the diazonium coupling reaction of two different aromatic amines, using nano silicagel supported by thionyl chloride as a solid acid. It could be drawn from the results that using this new method in order to synthesis the dyes based on 2-naphthol is economical and harmless to the environment due to the elimination of dense liquid acids. The dyes can be provided by the use of silica gel base in room temperature, with a high yield, in a short time and above all, with no use of dense liquid acids. After synthesis, the dyes were applied to wool and nylon fibers, and their technical properties on the fibers were investigated. The dyes showed an acceptable dyeability and good wash fastness on both fiber types. Besides, the light fastness on nylon and wool fibers was shown to be moderate and good, respectively.

\section{Acknowledgment}

We gratefully acknowledge financial support from the Research Council of Islamic Azad University of Yazd and The Islamic Azad University of Zahedan of Iran. 


\section{References}

1. Yazdanbakhsh M R, Giahi M and Mohammadi R, J Mol Liq., 2009, 144, 145.

2. Catino S C and Farris R E, Azo dyes, Concise Encycolopedia of chemical technology, John wiley \& Sons Inc., Newyork: Grayson M (Ed.), 1985, 142.

3. Manuela M, Raposo M, Sousa A, Maurico A, Fonseca C and Kirsch G, Tetrahedron, 2005, 61, 8249.

4. Karci F, Demircali A, Sener I and Tilki T, Dyes Pigm., 2006, 71, 90.

5. Yazdanbakhsh M R, Ghanadzadeh A and Moradi E, J Mol Liq., , 2007, 136, 165.

6. Van der Zee F P, Anaerobic azo dye reduction. Doctoral Thesis; Wageningen University; Wageningen; The Netherlands, 2002.

7. Li Y, Zhang S, Yang J, Jiang S and Li Q, Dyes Pigm., 2008, 76, 508.

8. Gharanjig K, Arami M, Bahrami H, Movassagh B, Mahmudi M and Niyaz Rouhani S, Dyes Pigm., 2008, 76, 684.

9. Sokolowska J, Podsiadly R and Sochocka E, Dyes Pigm., 2007, 72, 223.

10. Yadav J S, Subba Reddy B V and Srinivas Reddy A, J Mol Catal A: Chem., 2008, 280, 219.

11. Wilson K and Clark J H, Pure Appl Chem., 2000, 72, 1313.

12. Dabbagh H A, Teimouri A and Chermahini A N, Dyes Pigm., 2007, 73, 239.

13. Li F, Chen W, Dong P and Zhang S, Biosens Bioelectron., 2009, 24, 2160.

14. Gorlushko D A, Filimonov V D, Krasnokutskaya E A, Semenischeva N I, Go B S, Hwang H Y, Cha E H and Chi K W, Tetrahedron Lett., 2008, 49, 1080.

15. Faustino H, El-Shishtawy R M, Reis L V, Santos P F and Almeida P, Tetrahedron Lett., 2008, 49, 6907.

16. Ramachary D B, Narayana V V and Ramakumar K, Tetrahedron Lett., 2008, 49, 2704.

17. Lyčka A, Koloničnỳ A, Simůnek P and Machaček V, Dyes Pigm., 2007, 72, 208.

18. Noroozi N P, Khalafy J and Malekpoor Z, J Chin Chem Soc., 2009, 56, 1018. 


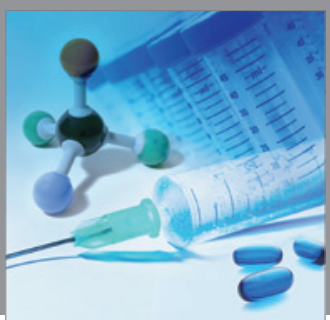

International Journal of

Medicinal Chemistry

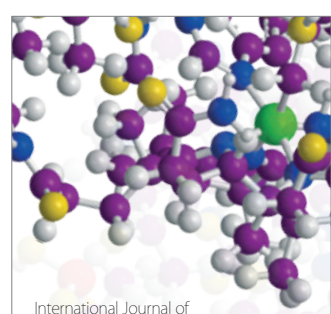

Carbohydrate Chemistry

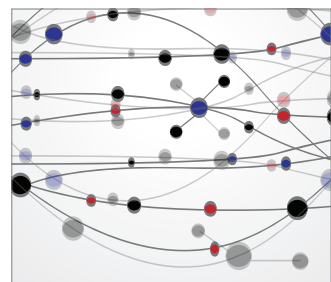

The Scientific World Journal
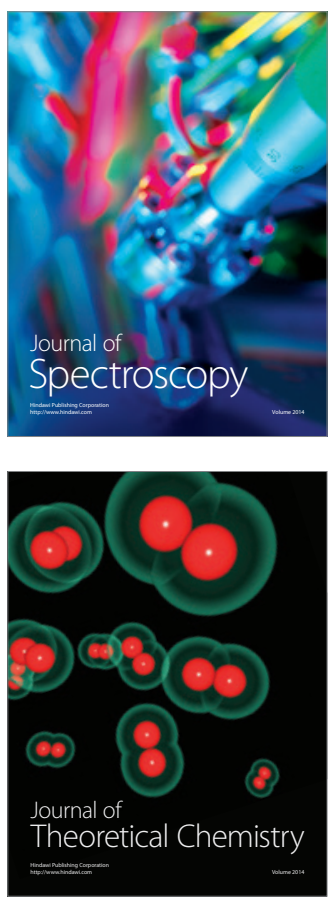
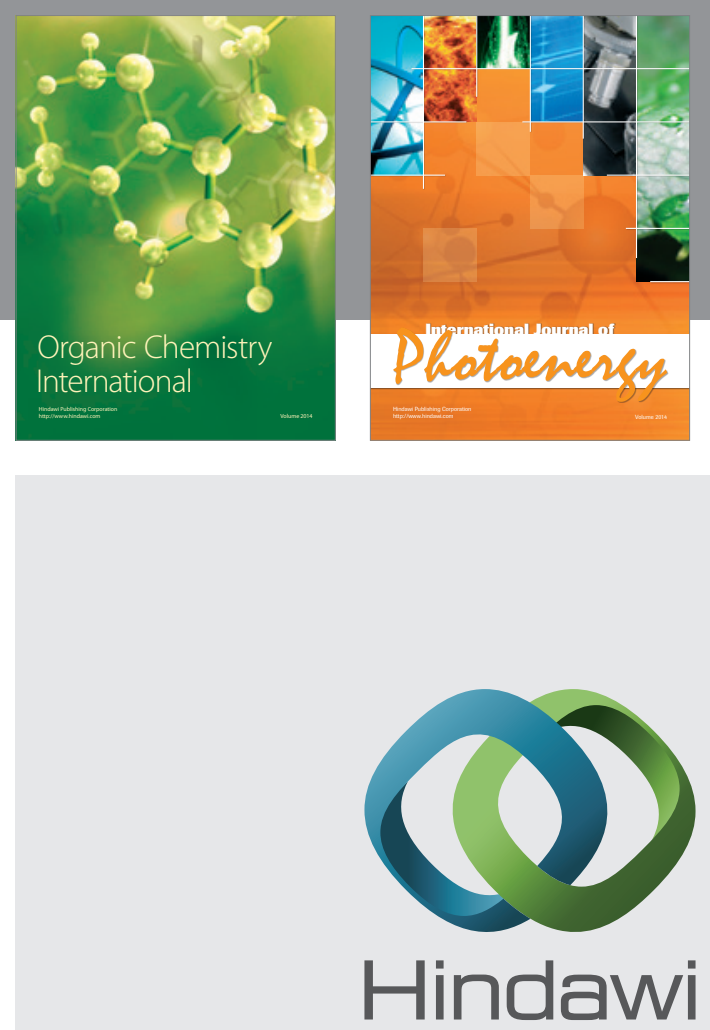

Submit your manuscripts at

http://www.hindawi.com
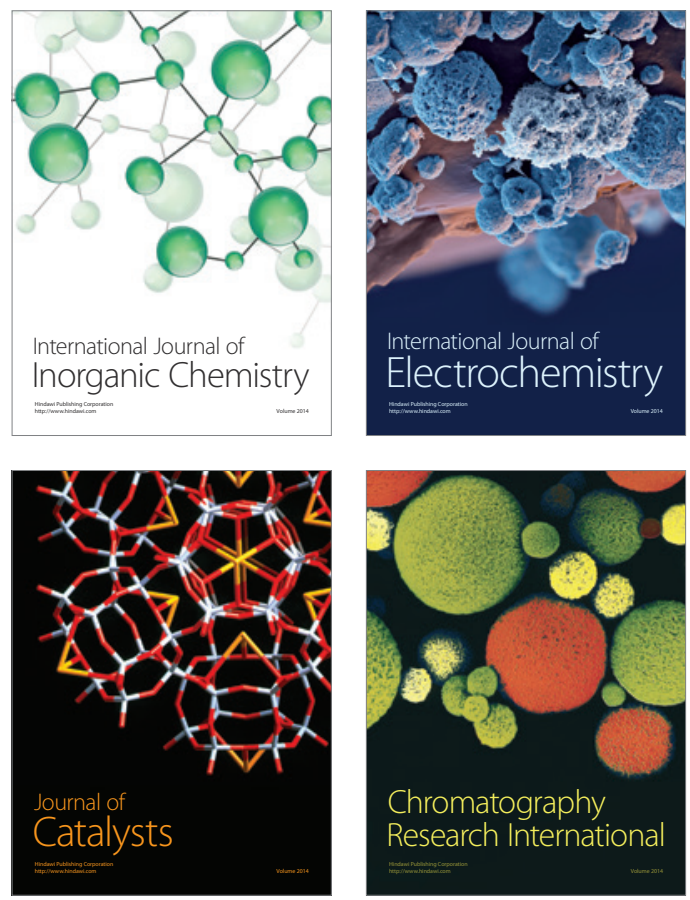
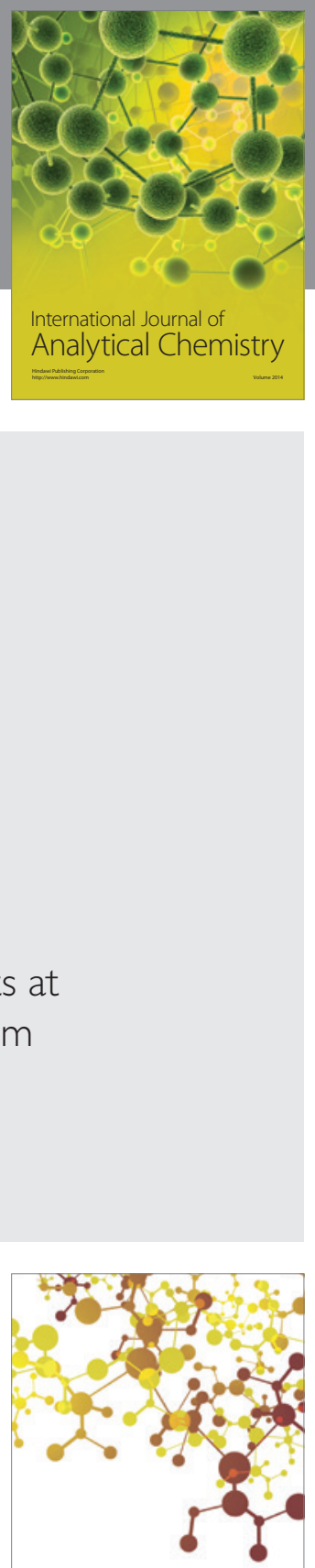

Journal of

Applied Chemistry
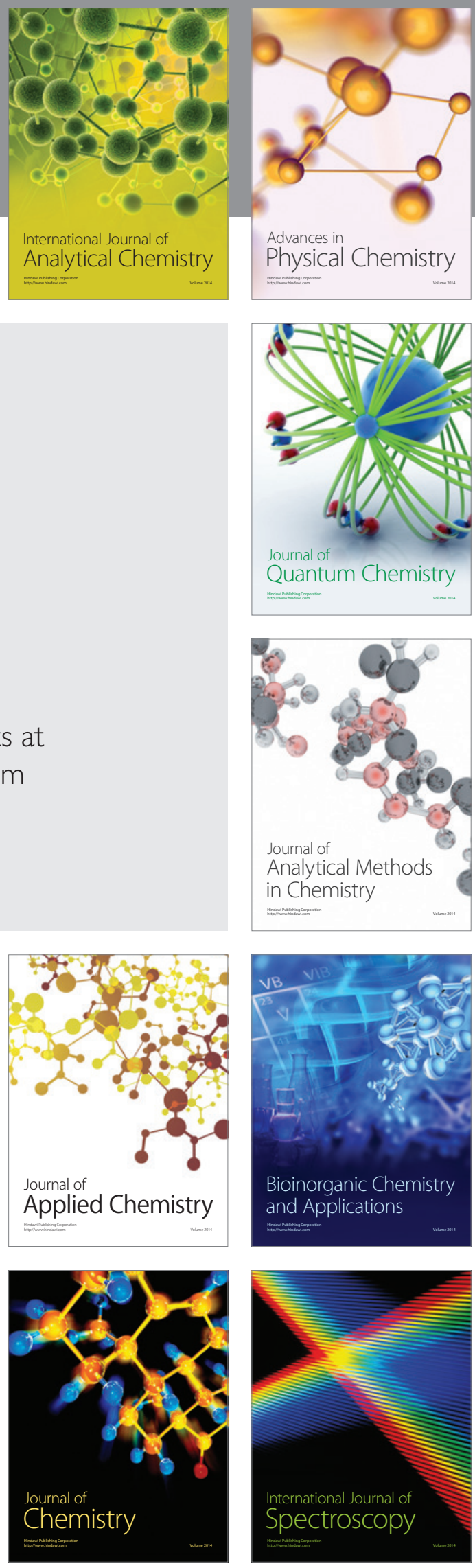